\title{
Quando romance e a violência se entrecruzam: interface nos relacionamentos entre adolescentes
}

\author{
When dating and violence between: interface in relationships between adolescents \\ Cuando el romance y la violence entre: interfaz em las relaciones entre adolescentes \\ Greice Kely Oliveira de Souza ${ }^{1 *}$, Sinara de Lima Souza ${ }^{1}$, Maria Lúcia Silva Servo¹, Rosely Cabral \\ de Carvalho', Alba Benemérita Alves Vilela², Tamyres Lopes Santana de Carvalho'.
}

\section{RESUMO}

Objetivo: Descrever as justificativas para a existência da violência nas relações de intimidade para os participantes da pesquisa. Métodos: Consistiu em um estudo qualitativo, descritivo, recorte do projeto "Representações sociais de adolescentes e jovens acerca da violência nas relações de intimidade" aprovado pelo Comitê de Ética da Universidade Estadual de Feira de Santana, parecer no 2.098.268. Os dados foram coletados por meio de roda de conversa, técnica projetiva temática e entrevista semiestruturada, com adolescentes escolares de ambos os sexos, com idade entre 11 a 16 anos. Para análise de dados, utilizou-se a análise de conteúdo e nuvem de palavras com o software IRAMUTEQ®. Resultados: Os adolescentes justificam os diversos tipos de violência nas relações de intimidade pelo ciúme e infidelidade, a nuvem identifica as palavras: mulher, traição, ciúme e violência com a mesma força. Conclusão: Representações e valores machistas e sexistas, apesar de retrógradas, endossam a violência entre parceiros íntimos, perpetradas através das agressões físicas e psicológicas.

Palavras-chave: Violência, Ciúmes, Violência por parceiro íntimo, Adolescente, Violência de gênero.

\begin{abstract}
Objective: To describe the justifications for the existence of violence in intimate relationships for the research participants. Methods: It consisted of a qualitative, descriptive study, part of the project "Social representations of adolescents and young people about violence in intimate relationships" approved by the Ethics Committee of the State University of Feira de Santana, opinion No. 2.098.268. Data were collected through a conversation wheel, thematic projective technique and semi-structured interview, with school adolescents of both sexes, aged 11 to 16 years. For data analysis, content analysis and word cloud were used with the IRAMUTEQ® software. Results: Adolescents justify the various types of violence in intimate relationships by jealousy and infidelity, the cloud identifies the words: woman, betrayal, jealousy and violence with the same force. Conclusion: Sexist and sexist representations and values, although retrograde, endorse violence between intimate partners, perpetrated through physical and psychological aggressions.
\end{abstract}

Keywords: Violence, Jealous, Intimate partner violence, Adolescent, Gender violence.

\section{RESUMEN}

Objetivo: Describir las justificaciones de la existencia de violencia en las relaciones íntimas para los participantes de la investigación. Métodos: Consistió en un estudio cualitativo, descriptivo, parte del proyecto "Representaciones sociales de adolescentes y jóvenes sobre la violencia en las relaciones íntimas"

1Universidade Estadual de Feira de Santana (UEFS), Feira de Santana - BA.

*E-mail: greicekely@hotmail.com.br

2Universidade Estadual do Sudoeste da Bahia (UESB), Jequié - BA. 
aprobado por el Comité de Ética de la Universidad Estatal de Feira de Santana, opinión No. 2.098.268. Los datos fueron recolectados a través de una rueda de conversación, una técnica proyectiva temática y una entrevista semiestructurada, con adolescentes escolares de ambos sexos, de 11 a 16 años. Para el análisis de datos, el análisis de contenido y la nube de palabras se utilizaron con el software IRAMUTEQ®. Resultados: Los adolescentes justifican los diversos tipos de violencia en las relaciones íntimas por celos e infidelidad, la nube identifica las palabras: mujer, traición, celos y violencia con la misma fuerza. Conclusión: Las representaciones y valores sexistas y sexistas, aunque retrógrados, respaldan la violencia entre parejas íntimas, perpetrada a través de agresiones físicas y psicológicas.

Palabras clave: Violencia, Celoso, La violencia de pareja, Adolescente, Violencia de género.

\section{INTRODUÇÃO}

O namoro é entendido como uma relação diádica, ou seja, entre duas pessoas, envolvendo uma interação social e o desejo de realizar atividades conjuntas (ALDRIGHI T, 2004). As interações amorosas construídas ao longo da vida assumem grande relevância para os adolescentes, o que poderá conferir uma segurança emocional em um momento no qual há o distanciamento da família.

Este tipo de relacionamento é caracterizado, sobretudo, por uma compreensão implícita do grau de envolvimento, ou seja, pela estabilidade da associação entre duas pessoas, que é inversamente relacionado à probabilidade de uma pessoa terminar a relação. Além da causalidade embutida no surgimento do compromisso é necessário atentar o que deixa os pares unidos (MARTINS A, PEREIRA M, CANAVARRO MC, 2014).

Devido às transformações sociais ocorridas, modificando as relações de intimidade e surgindo novas formas de se nomear um relacionamento, alguns autores sintetizaram o "ficar", o "pegar" e o "namorar" com a mesma definição, referindo que podem ocorrer ao mesmo tempo (MURTA A, et al., 2013; SILVA LM, et al., 2017).

Esses protótipos de relacionamento são replicados também no âmbito dos namoros, afetos e das intimidades entre adolescentes, ponderando que a escola é um dos principais ambientes de sociabilidade dos adolescentes, o exercício da sexualidade se constitui uma realidade na vivência escolar. As primeiras vivências afetivas e íntimas se dão, assim, em um contexto de produção e reprodução de relevantes desigualdades marcadas por subalternizações diversas de gênero, raça e sexualidade (BESERRA MA, et al., 2015).

A violência no namoro pode ser conceituada como uma prática ou ameaça de um ato de violência que ocorre com um dos membros de um casal de namorados, seja do mesmo sexo ou do sexo oposto. Ocorre de forma gradual nas relações e apresenta-se nas mais diversas tipologias de violência (psicológica, física ou sexual) podendo mostrar-se sob a forma do menor abuso a situações mais extremas como o assassinato (NASCIMENTO FS e CORDEIRO RL, 2011; BESERRA MA, et al., 2015).

$\mathrm{Na}$ última década, no Brasil, os estudos acerca da violência no namoro tiveram grande avanço como campo de investigação e intervenção, porém a maior parte da produção é destinada a violência contra a mulher de uma forma geral, apesar dos primeiros estudos serem a respeito de casais casados, o tema foi estendido para relacionamentos de namoro, principalmente na América do Norte, sendo menos frequente na Europa, América Latina, África e Ásia (MURTA A et al., 2013; SOARES JS, LOPES MJ, NJAINE K, 2013).

$\mathrm{Na}$ interface da violência nas relações íntimas entre adolescentes, os estudos são cada vez mais necessários, a princípio, por existirem altas taxas de prevalência da violência no namoro em vários países e o impacto psicossocial da violência no namoro que é um grande problema de saúde pública (MURTA A, et al., 2013; BESERRA MA, et al., 2015; PIMENTEL CE, MOURA GB e CAVALCANTI JG, 2017). Assim sendo, o estudo teve como objetivo geral descrever as justificativas para a existência da violência nas relações de intimidade para os participantes da pesquisa. 


\section{MÉTODOS}

Estudo qualitativo, exploratório e descritivo fundamentado na Teoria das Representações Sociais. A coleta de dados aconteceu entre os meses de fevereiro a julho de 2019. Os participantes do estudo foram adolescentes de ambos os sexos cursando o ensino fundamental de uma escola da rede pública municipal da cidade de Feira de Santana - BA. A faixa etária foi de 11 a 16 anos. O grupo de sujeitos foi definido a partir da saturação dos dados, homogeneidades e as diferenciações internas do grupo pesquisado. Foram excluídos da pesquisa adolescentes que possuíam alguma patologia que impossibilitasse a sua participação e aqueles que evadiram da escola.

As técnicas de coleta de dados desse estudo foram técnicas projetivas temáticas do tipo desenho-estória com tema, a roda de conversa e a entrevista semi-estruturada. A roda de conversa iniciou com uma dinâmica de aproximação do tema, em seguida foi apresentada a técnica desenho-estória com tema, solicitando que os adolescentes fizessem uma estória, um desenho e desse um tema, a partir do indutor, violência no namoro, ao término das produções, os adolescentes apresentaram os resultados para a classe de forma a socializar o conteúdo. Em outro momento, foram realizadas as entrevistas com os participantes do desenho-estória com tema e da roda de conversa.

Os dados foram analisados em duas etapas complementares: por meio dos pressupostos da Análise de Conteúdo proposto por Bardin e pela utilização do software IRAMUTEQ®. O conteúdo dos desenhos-estória com tema, roda de conversa e entrevistas semi-estruturadas foi transcrito na íntegra e submetidos a análise qualitativa de conteúdo de Bardin, o qual se define como um conjunto de técnicas e análise das comunicações, utilizando procedimentos sistemáticos e objetivos divididos em três fases relativos a recepção dessas mensagens (BARDIN L, 2011; CAMARGO BV e JUSTO AM, 2018).

O software permite várias formas de análise de dados textuais, abrangendo desde as mais simples como a lexicografia - Cálculo da Frequência de Palavras - até as análises multivariadas - Classificação Hierárquica Descendente (CHD), análises de similitude (CAMARGO BV e JUSTO AM, 2018).

Neste estudo, acatamos a resolução 466/2012, que dispõe sobre a Ética em Pesquisa envolvendo seres humanos, contendo aspectos relativos à justificativa, aos objetivos e metodologia da pesquisa, bem como a garantia total do sigilo dos dados que serão obtidos dos adolescentes que concordarem a participar da pesquisa.

Este estudo é um recorte do projeto de pesquisa iniciado em 2017, intitulado "Representações Sociais dos adolescentes e jovens acerca da violência nas relações de intimidade", sob o parecer $n^{\circ} 2.098 .268$, desenvolvido pelo Núcleo Interdisciplinar de Estudos sobre Vulnerabilidades e Saúde (NIEVS), da Universidade Estadual de Feira de Santana (UEFS). Os participantes assinaram o Termo de Assentimento (TALE) e os pais e/ou responsáveis assinaram o Termo de Consentimento Livre e Esclarecido (TCLE) (BRASIL, 2012).

\section{RESULTADOS}

O ciúme foi o maior causador da violência, apresentando-se como fator determinante para ocorrência da violência nos relacionamentos e agregando-se também a infidelidade como disruptores de conflitos e brigas. As falas a seguir reforçam:

Ciúme causa violência. (Ent_01)

Tem ciúme, todos nós temos ciúmes, quando não tem ciúme é porque não tem sentimento. (Ent_10)

Existe a violência através dos ciúmes. (Ent_11)

A manutenção de um controle utópico sobre o(a) parceiro(a) como prevenção de brigas ou o ciúme como demonstração de amor são opostos na trama das relações amorosas. Constatou-se a existência da crença e do sonho de um amor romantizado, de que o outro é a "alma gêmea" e de que só existe a felicidade quando se estiver com o outro. Essa idealização foi expressa de inúmeras formas, algumas mais sutis e outras mais explícitas. 
Porque o mundo hoje tá assim. Ciúmes. Ciúme causa violência, principalmente ciúmes possessivos. (Ent_01)

Eu vejo assim, porque eu tando apaixonada por uma pessoa, se eu vê[...], certo que, tem ciúme, todos nós temos ciúmes..." (Ent_10)

Então se você tá com aquela pessoa, vo9cê não pode sentir ciúme, você tem que confiar nela [...] A maioria das vezes os ciúmes que causa essa violência [...] Eu acho que é ciúmes quando não deixa sair com uma roupa [...] (Ent_12)

O sentimento de ciúme incitado por situações de infidelidade (verdadeiras ou suposições) é desencadeador de desordens que resultam em violência durante o namoro em contextos culturais distintos (Figura 1).

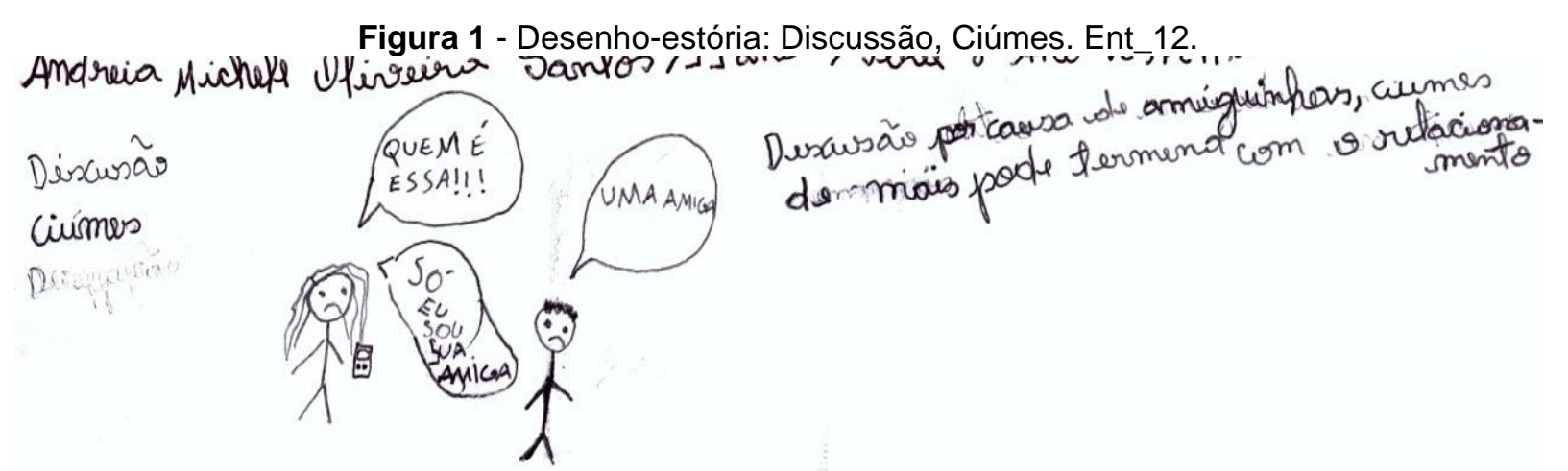

Fonte: SOUZA GK et al, 2020.

A violência mostrada na figura é causada por "ciúmes demais". O ciúme é percebido como algo ruim ou negativo pelos adolescentes somente quando é considerado exacerbado. Tornando-se visível através de comportamentos controladores ou de agressões diversas, inclusive físicas. Outro ponto importante é o fato do uso do celular, como mostra o desenho. O uso das tecnologias, como o celular, é um dos motivos retratados na roda de conversa e identificados nessas falas:

Pode pegar o celular desbloqueado[...] (RC2_N14)

Tem que dá o celular, se não tá escondendo. (RC2_N05)

Se não der o celular tem briga. (RC1_N08)

A nuvem de palavras elaborada pelo IRAMUTEQ® representa de forma gráfica a organização e agrupamento das palavras de acordo com a sua frequência, o que possibilita facilmente a sua identificação, a partir de um único arquivo, o corpus textual, que reúne os textos originados das entrevistas, correspondente a segunda questão norteadora, o desenho-estória e a roda de conversa.

A representação em nuvem de palavras trata-se de uma análise lexical mais simples, entretanto, com uma ilustração gráfica que permite com facilidade e rapidez a identificação das palavras-chave de um corpus. Conceitua-se corpus textual como o conjunto de unidades de contexto inicial (UCl) que se pretende analisar, e é elaborado pelo pesquisador. Cada conjunto de entrevistas a que a análise foi aplicada será um texto (CAMARGO BV e JUSTO AM, 2018).

O vocabulário é processado e quantificado em relação à frequência e, em determinados casos, são submetidos a cálculos estatísticos para obter sua posição no texto, para posterior interpretação, sendo uma das diferenças da análise de conteúdo, no qual o pesquisador interpreta para depois sistematizar (KAMI MT, et al, 2016).

Pelo método da nuvem de palavras, a palavra mulher foi a que teve uma maior frequência no corpus 27 vezes, seguida da palavra violência, 25 vezes. As palavras ciúmes e traição tiveram a mesma frequência e por isso o mesmo tamanho, as palavras são posicionadas aleatoriamente de tal forma que as palavras 
mais frequentes aparecem maiores que as outras. Nesse sentido, observa-se que os adolescentes representam que o ciúme e a infidelidade são as motivações para ocorrência da violência, como já foi reafirmado através da análise dos outros instrumentos de coleta (Figura 2).

Figura 2 - Nuvem de Palavras elaboradas pelo software IRAMUTEQ®.

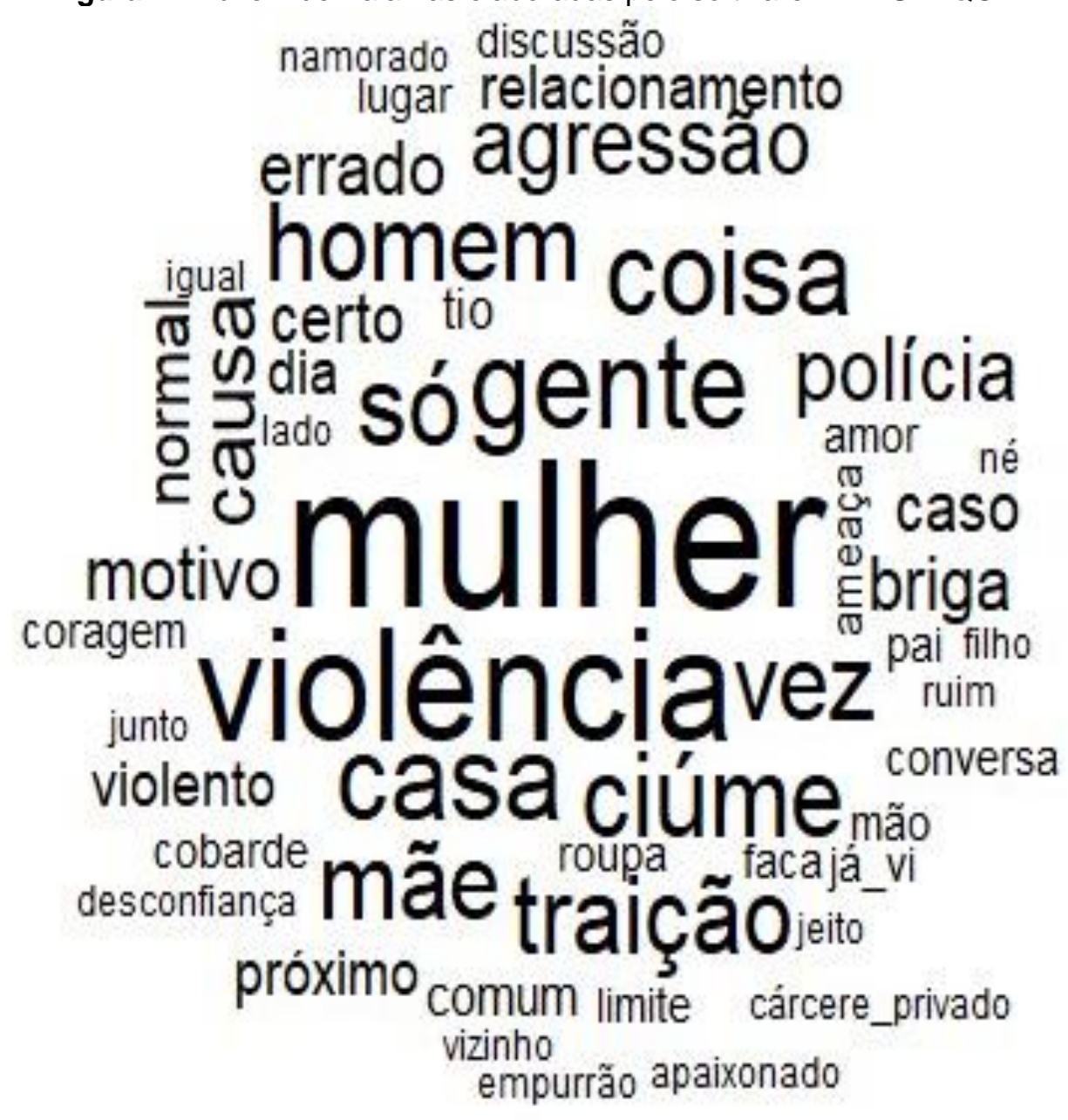

Fonte: SOUZA GK et al, 2020.

Neste sentido, um estudo em 10 capitais brasileiras observou que a violência física, sendo mais comuns em mulheres, como tapas no namorado, era causada por ciúmes e/ou traição (MINAYO MC, ASSIS SG e NJAINE K, 2011). Bem como observado nas falas dos adolescentes durante a entrevista e as rodas de conversa:

Quando a gente tá com ciúmes, um do outro, ai a gente vai e bate um no outro, porque fica mentindo, essas coisas assim, ai eu bato na cara dele. (Ent_09)

Traição pode gerar uma briga e de uma briga pode agredir o outro. (Ent_02)

Não sair com outro, só tem brigas e violência quando tem traição. (Ent_05)

Rolou traição e ela gosta. Por isso tocou fogo. (RC1_N05)

Óh quando acontece de uma mulher bater nele, eu acho que porque ela chegou no seu limite... (Ent_10).

Observa-se um desenho-estória baseado na traição e por isso evidencia-se a violência. Várias respostas e reações verbais auxiliam nessa temática da traição envolvendo violência, em alguns momentos das rodas de conversa a discussão foi motivada com expressões a atitudes violentas (Figura 3). 
Figura 3 - O desenho-estória - A traição.

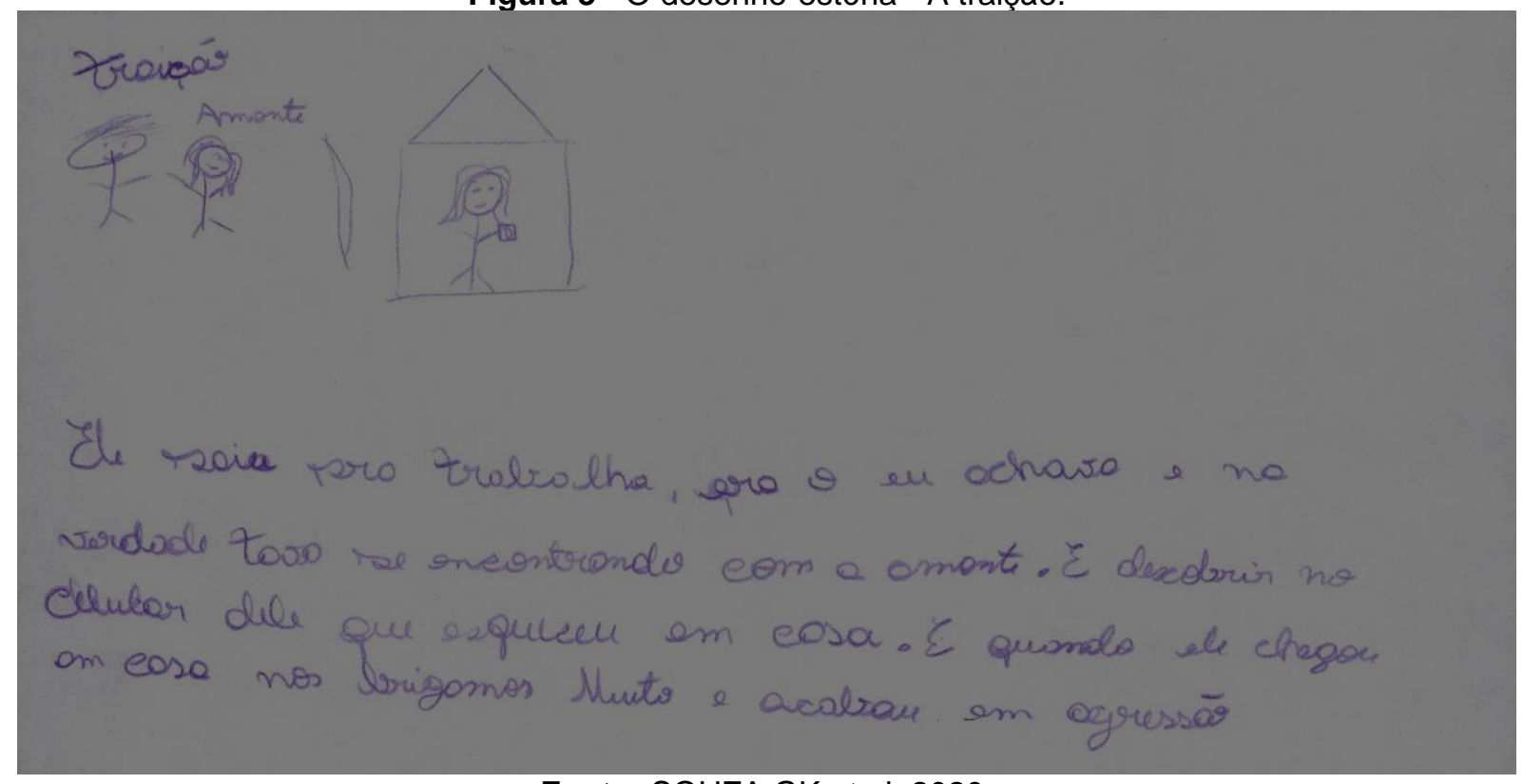

Fonte: SOUZA GK et al, 2020.

Outro dado importante, que apareceu durante a entrevista e um desenho estória, foi a relação violênciabebida, como ilustrado nas falas a seguir (Figura 4):

Ele já chegava bebendo e batendo nela. Sem motivo. O motivo é a bebida. (Ent_06)

Eu acho que a bebida é uma desculpa. Quando ele bebe muito, ele não sabe o que tá fazendo [...] ai ele fica [...] Tem gente quando bebe muito bate na mulher[...] (Ent_08)

Figura 4 - Desenho-estória: Agressão - Ent_08.

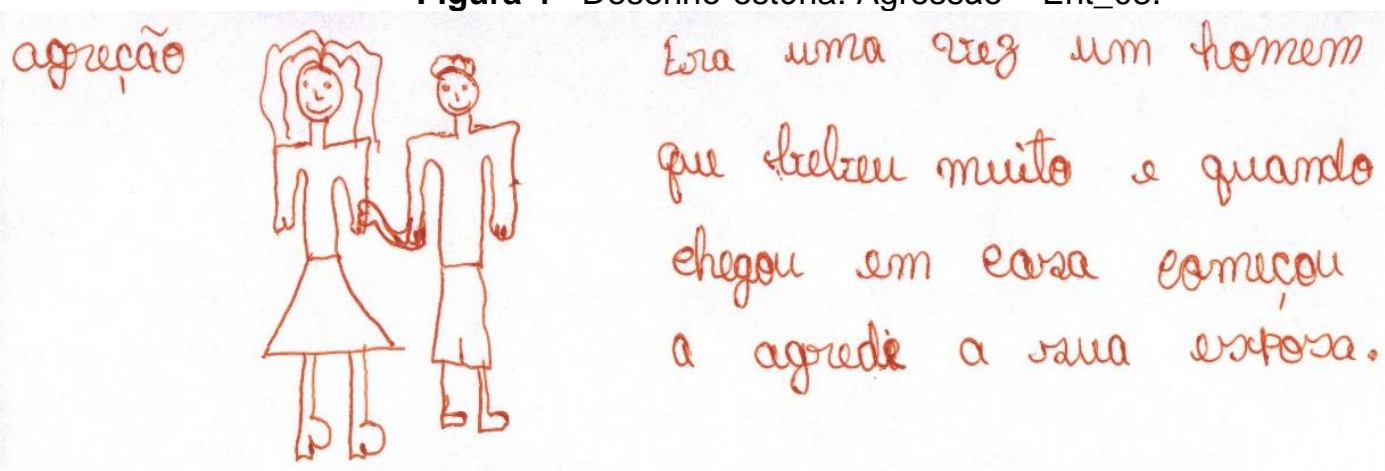

Fonte: SOUZA GK et al, 2020.

A adolescente retrata situação vivenciada em seu cotidiano. Em relação a isso (SÁ CP, 1998), relata que as representações sociais, por seu poder convencional e prescritivo sobre a realidade, reproduzem um aspecto da vida cotidiana. Assim, as representações foram voltadas para aspectos afetivos e familiares, ancoradas em explicações psicológicas e interações microssociais, que se dão no plano das relações familiares, do ambiente em que vivem, da sociedade ou da escola (Figura 4).

\section{DISCUSSÃO}

A noção de um amor romântico, singelo e puro, capaz de ultrapassar todas as barreiras em busca da plenitude do amor tem sido vinculada ao longo do tempo. Esse conceito é um mito e, para tanto, é acompanhado por diversos elementos incluindo o ciúme, a eternidade do amor, a relação amor-sofrimento, a traição, o amor eterno e a honra. Várias situações antagônicas ao que se espera do amor ideal pode 
ocorrer e a justificativa dos indivíduos gira em torno de que pelo amor tudo se supera e aceita para estarem juntos do seu amado (a), não desenvolvendo uma percepção de que cada desejo funciona como uma forma de dominação e pode funcionar como um gatilho para episódios de violência nos relacionamentos de intimidade (SELGAS FJ e APARÍCIO EC, 2010; LOW TS e MELO DS, 2012).

$\mathrm{Na}$ literatura internacional, autores portugueses constataram que, nas relações afetivas no namoro entre adolescentes, o ciúme exerce papel de expressão de amor, mesmo de forma confusa e de justificativa para a violência. A violência é percebida como forma de advertência para as mulheres e, diferentemente, para os homens como resposta às "provocações femininas". Taquette SR, et al (2003), no mesmo sentido traz um achado importante e preocupante, pois detectou que os adolescentes consideraram normal a agressão verbal ou física na resolução de conflitos, tendo como principal causa, o ciúme, justificando a ocorrência de violência e desrespeito (GAMA A, VERÍSSIMO A e TOMAS C, 2017; BITTAR DB e NAKANO AM, 2017).

O ciúme como o principal responsável pelos atos violentos vem sendo realçado também por outros autores que asseguram que o namorado briguento é, não raras vezes, visto como protetor e a expressão de ciúme exagerado considerada uma nova prova de amor. Esse achado corrobora, com alguns estudos que obtiveram resultados parecidos (LOW TS e MELO DS, 2012; TAQUETTE SR, et al, 2003; VIDAL El e RIBEIRO PR, 2008; SOUZA SL, CARVALHO RC e AMARO P, 2019).

As falas encontradas, são representações de que o ciúme é utilizado como forma de validar a violência, "o sentimento é percebido por nós sob a forma de ciúme, cólera, ultraje, ofensa" (VIGOTSKY LS, 2004, p. 126). Estudos nacionais e internacionais apontam o papel do ciúme, como enfático, nas brigas entre parceiros íntimos adolescentes (MURPHY KA e SMITH DI, 2010; OLIVEIRA RN, et al., 2016).

O controle do uso do celular, devido às redes sociais expõe a fragilidade das relações de intimidade, haja vista a desconfiança mútua, representando uma ameaça ou má influência. O aparelho celular retratado em face ao ciúme também esteve presente no estudo sobre a percepção dos adolescentes que vivenciaram a violência nos relacionamentos íntimos (CAMPEIZ AB, et al., 2017). Segundo as autoras, a violência surge pelo desejo do parceiro (a) em manifestar através da insistência do (a) parceiro (a) em cobiçar a senha do celular e das redes sociais, ocasionando no controle, na manipulação e invasão de privacidade.

Alves-Mazzotti AJ (2008) argumenta que as representações facilitam as redes de relações, onde existe a ligação dos comportamentos e objetos. Nessas relações, os indivíduos ou coletividades modificam o jeito de ver, de forma a influenciar e se remodelar reciprocamente. Pode-se, então, influenciar o pensamento das pessoas e a forma como elas se relacionam com o mundo. Diante disso, os estudos em representações sociais permitem a aproximação com o fenômeno complexo e multifacetado da violência nas relações de intimidade, com a elaboração e construção do conhecimento do senso comum sobre esse objeto e, por fim, com a construção da realidade social.

Os resultados do presente estudo reforçam relatos da literatura sobre a existência de violência verbal e psicológica manifestada pela demonstração de ciúmes, o desejo de controle do parceiro e a traição (CECCHETTO F, et al, 2016; OLIVEIRA QB et al., 2014). Nota-se que as falas demonstram que a agressão é derivada de uma traição ou de ciúmes, sendo uma justificativa para os atos violentos. A violência por parte dos adolescentes do sexo feminino está intensamente associada a sentimentos de raiva, hostilidade frente à traição e à violência perpetrada pelo parceiro; portanto, suas atitudes violentas frequentemente são decorrentes de uma autodefesa (COELHO EB, SILVA AC e LINDNER SR, 2018).

Outro dado que chamou atenção foi a relação da violência com a bebida, pois os adolescentes referiram que a traição ocorria devido a utilização do álcool, considerada um pretexto. Nesse contexto, os relatos dos participantes se concentraram em situações vividas por seus pais e familiares, ou alguém próximo, nos quais a bebida aparece como viabilizadores da violência, não sendo especificada quanto ao tipo e duração do uso.

Nos relatos, a generalização do termo bebida, é relacionada ao uso de álcool, sendo uma RS de uma droga lícita e de fácil acesso. Diversos autores relatam sobre o uso do álcool como potencializador de comportamento de risco. Nesse intuito, há um consenso na relação entre o consumo de álcool pelo 
agressor como fator de risco para violência. Demonstrando que a perpetração da violência é devido ao álcool proporcionar uma inibição e redução no discernimento, levando a condutas primitivas (SILVA LM, et al., 2017; SOUZA SL, CARVALHO RC e AMARO P, 2019; SILVA AC, COELHO EB e MORETTI-PIRES RO, 2014).

Isso mostra a importância de se apreender as representações sociais, uma vez que fazem parte de um contexto, de um cenário próprio. O saber latente foi identificado através das falas e dos sentidos construídos pelos participantes, pois as RS orientam e organizam as condutas e as comunicações sociais.

\section{CONSIDERAÇÕES FINAIS}

Mudanças profundas ocorreram no campo das relações, atravessando assim, o estilo de vida dos adolescentes, transformando-se o ideal de relações afetivo-sexuais igualitárias, harmônicas e proporcionais. Porém, os resultados desse estudo revelam o quanto ainda persistem valores retrógrados e machistas apoiados no ciúme e na infidelidade que acabam por endossar a violência entre parceiros íntimos e que são justificadas através das agressões físicas contra seus namorados. A perpetuação de práticas violentas surge principalmente pela forma como a violência é percebida e reproduzida no cotidiano. Os relacionamentos íntimos baseados nos princípios de posse e ciúme legitimaram a violência, abonaram ações irrefletidas e isentaram a responsabilidade do autor da violência. Essas novas concepções e significados são imprescindíveis para o desenvolvimento de relações de intimidade saudáveis, que comportem diferenças e complementariedades entre os múltiplos elementos que as compõem e entre as partes e o todo; ou seja, os elementos/partes formam o todo das relações de modo a manter sua interdependência. Por isso a importância de se refletir sobre formas de existência das relações afetivosexuais que não sejam meras disseminadoras de uma lógica de dominação, mas sim, o despertar de uma consciência, sendo necessário a construção de formas de relacionamento saudáveis que estejam bem diferentes as formas tradicionais que reificam a violência como meio de resolução de conflitos.

\section{REFERÊNCIAS}

1. ALDRIGHI T. Prevalência e cronicidade da violência física no namoro entre jovens universitários do Estado de São Paulo. Psicologia Teoria e Prática [Internet]. 2004.

2. ALVES-MAZZOTTI AJ. Representações Sociais: aspectos teóricos e aplicações à educação. Rev. Múltiplas Leituras [Internet]. 2008; 1(1).

3. BARDIN L. Análise de conteúdo. São Paulo: Edições 70; 2011.

4. BESERRA MA, et al. Prevalência de Violência no Namoro entre Adolescentes de Escolas Públicas de Recife/Pe Brasil. Rev. Enf. Ref. [Internet]. 2015; serIV(7).

5. BITTAR DB, NAKANO AMS. Symbolic violence among adolescents in affective dating relationships. Rev. esc. enferm. USP [Internet]. 2017; 51.

6. CAMARGO BV, JUSTO AM. Tutorial para uso do Software IRAMUTEQ (Interface de R pour les Analyses Multidimensionnelles de Textes et de Questionnaires). Laboratório de Psicologia Social de Comunicação e Cognição - UFSC. [Internet]. 2018.

7. CAMPEIZ AB, et al. Percepções de adolescentes que vivenciaram a violência no relacionamento íntimo à luz da Complexidade. Atas- Investigação qualitativa em saúde. [Internet]. 2017; 2.

8. CECCHETTO F, et al. Violências percebidas por homens adolescentes na interação afetivo-sexual em dez cidades brasileiras. Interface (Botucatu) [Internet]. 2016; 20(59).

9. COELHO EBS, SILVA ACLG, LINDNER SR. Violência por parceiro íntimo: definições e tipologias. In: COELHO EBS, SILVA ACLG, LINDNER SR. Curso atenção a homens e mulheres em situação de violência por parceiros íntimos - modalidade a distância. Florianópolis: Úniversidade Federal de Santa Catarina; 2018.

10. GAMA A, VERISSIMO A, TOMAS C. Violência no Namoro na Escola Superior de Educação de Lisboa. Ex aequo [Internet]. 2017; 36.

11. KAMI MTM, et al. Trabalho no consultório na rua: uso do software IRAMUTEQ no apoio à pesquisa qualitativa. Esc. Anna Nery [Internet]. 2016; 20(3).

12. LOW TSJ, MELO DSP de. O mito do amor romântico e a violência de gênero: distanciamentos e aproximações nas vozes de meninas e meninos adolescentes. In: Simpósio Internacional sobre a Juventude Brasileira; 2012; Recife, Brasil. Recife: UFPE; 2012.

13. MARTINS A, PEREIRA M, CANAVARRO MC. Comportamentos extra-diádicos nas relações de namoro: Diferenças de sexo na prevalência e correlatos.Aná. Psicológica [Internet]. 2014; 32(1).

14. MINAYO MCS, ASSIS SG, NJAINE K. (Orgs.). Amor e Violência: um paradoxo das relações de namoro e do "ficar" entre os jovens brasileiros. Rio de Janeiro: Fiocruz; 2011. 
15. Ministério da Saúde (BR). Conselho Nacional de Saúde. Diretrizes e normas regulamentadoras de pesquisa envolvendo seres humanos. Resolução n. 466, de 12 de dezembro de 2012. Brasília; 2012

16. MURPHY KA, SMITH DI. Adolescent girls' responses to warning signs of abuse in romantic relationships: Implications for Youth-targeted relationship violence prevention. Journal of Interpersonal Violence, [Internet]. 2010; 25(4).

17. OLIVEIRA RNG, et al. Preventing violence by intimate partners in adolescence: an integrative review. Rev. esc. enferm. USP [Internet]. 2016; 50(1).

18. OLIVEIRA QBM,et al. Namoro na adolescência no Brasil: circularidade da violência psicológica nos diferentes contextos relacionais. Ciênc. saúde coletiva [Internet]. 2014; 19(3).

19. MURTA SG, et al. Prevenção à violência no namoro e promoção de habilidades de vida em adolescentes. Psicol. USP [Internet]. 2013; 24(2).

20. NASCIMENTO FS, CORDEIRO R de LM. Violência no namoro para jovens moradores de Recife. Psicol. Soc. [Internet]. 2011;23(3).

21. PIMENTEL CE, MOURA GB de, CAVALCANTI JG. Acceptance of Dating Violence Scale: Checking its psychometric properties. Psico-USF [Internet]. 2017; 22(1).

22. SÁ CP de. A construção do objeto de pesquisa em representações sociais. Rio de Janeiro: EDUERJ; 1998.

23. SELGAS FJG, APARICIO EC. Violencia em la pareja:gênero y vínculo. Madrid: TALASA; 2010.

24. SILVA LMP da, et al. Violência entre namorados adolescentes em Pernambuco, Brasil. Adolesc Saude, [Internet]. 2017; 14(3).

25. SILVA ACLG da, COELHO EBS, MORETTI-PIRES RO. O que se sabe sobre o homem autor de violência contra a parceira íntima: uma revisão sistemática. Rev. Panam. Salud pública [Internet]. 2014; 35 (4).

26. SOUZA SL, CARVALHO RC, AMARO $P$. Representações da violência nas relações de intimidade para os adolescentes escolares. In: CARVALHO RC; SOUZA SL; SANTOS NETO PA. (Orgs.). Violência nas Escolas: do diagnóstico a intervenção. Curitiba: CRV, 2019.

27. SOARES J dos SF, LOPES MJM, NJAINE K. Violência nos relacionamentos afetivo-sexuais entre adolescentes de Porto Alegre, Rio Grande do Sul, Brasil: busca de ajuda e rede de apoio. Cad. Saúde Pública [Internet]. 2013; 29(6).

28. TAQUETTE SR, et al. Relacionamento violento na adolescência e risco de DST/AIDS. Cad. Saúde Pública [Internet]. 2003; 19(5).

29. VIDAL EI, RIBEIRO PRM. Algumas reflexões sobre relacionamentos afetivos e relações sexuais na adolescência. Fractal, Rev. Psicol. [Internet]. 2008; 20(2).

30. VIGOTSKY, LS. Psicologia pedagógica. São Paulo: Martins Fontes; 2004. 